\title{
PERKEMBANGAN KURIKULUM PENDIDIKAN VOKASIONAL BERBASIS PADA KEBUTUHAN DUNIA INDUSTRI
}

\author{
Miftahrur Bin Afan dan Muhammad Rizki* \\ Universitas Negeri Padang \\ *Corresponding author, e-mail: teukumuhammadrizki20@gmail.com
}

\begin{abstract}
Abstrak - Pendidikan dan Pelatihan Vokasional merupakan salah satu pendidikan yang sangat penting dalam meningkatkan keterampilan dan pengetahuan siswa. Sekolah Menengah Kejuruan sebagai salah satu pendidikan vokasional berperan penting dalam menghasilkan lulusan yang berkualitas dan siap memasuki dunia kerja. Sekolah di Indonesia belum membentuk lulusan yang mempunyai soft skills dan hard skills yang memiliki kecocokan atau kesesuaian dengan Dunia Usaha/Dunia Industri dan pada akhirnya lulusan ketika memasuki dunia kerja akan mengalami kesulitan beradaptasi dengan perkembangan teknologi yang ada di industri. Artikel ini bertujuan untuk mendeskripsikan perkembangan kurikulum pendidikan vokasional berbasis pada kebutuhan industri. Penelitian ini menggunakan pendekatan penelitian kualitatif dengan jenis penelitian desain penelitian deskriptif. Teknik pengumpulan data dengan telaah kepustakaan di mana dalam pembuatan artikel ini dikutip dari artikel yang telah dipublikasi pada jurnal atau prosiding ilmiah. Pelaksanaan kurikulum pendidikan vokasional saat ini belum sesuai pada kebutuhan Dunia Industri menurut Mendikbud: Muhadjir Effendy dan Kemnaker, sehingga terjadi ketidakcocokan atau ketidaksesuaian dengan kebutuhan Dunia Usaha dan Dunia Industri (DUDI) termasuk masyarakat.
\end{abstract}

Kata Kunci : Kurikulum, Pendidikan Vokasional, Dunia Industri

\section{A. PENDAHULUAN}

Pendidikan vokasional merupakan pendidikan yang di dalamnya memuat kurikulum yang peka terhadap berbagai keperluan tenaga-tenaga ahli yang dibutuhkan dalam suatu dunia industri. Sekolah Menengah Kejuruan (SMK) merupakan salah satu pendidikan vokasi di Indonesia yang menyiapkan lulusannya untuk siap bekerja dengan bekal pengetahuan, keterampilan dan sikap kerja dalam bidang tertentu yang sesuai dengan kebutuhan dunia usaha dan dunia industri (DUDI), serta diharapkan dapat berwirausaha (Indriaturrahmi dan Sudiyatno, 2016). Sekolah Menengah Kejuruan (SMK) sebagai salah satu pemegang peranan yang penting dalam menyiapkan tenaga kerja dituntut agar dapat mengikuti permintaan pasar yang terus berubah dan berkembang. Peraturan Pemerintah Republik Indonesia No. 29 Tahun 1990 tentang pendidikan menengah pasal 3 ayat 2 juga menyebutkan bahwa SMK mengutamakan penyiapan siswanya untuk memasuki lapangan kerja/dunia kerja serta mampu mengembangkan sikap profesional dalam berkerja. 
Tujuan terfokus dari sekolah menengah kejuruan salah satunya yaitu mampu menghasilkan lulusan yang dapat memasuki dunia kerja. Permasalahan yang muncul adalah menuntut sekolah menengah kejuruan harus menyesuaikan dengan dunia industri, namun SMK juga membutuhkan fasilitas praktik sebagai pendukung pelaksanaannya (Indriaturrahmi dan Sudiyatno, 2016). Namun dari lulusan sekolah menengah kejuruan yang siap masuk ke dunia kerja tidaklah banyak. Hal ini terjadi karena apa yang dipelajari siswa ketika disekolah tidak sesuai dengan kebutuhan dunia industri. Dalam pelaksanaannya kurikulum selalu bersifat dinamik untuk menghadapi berbagai perubahan dalam pendidikan (Yoto dkk., 2013). Tak dapat dipungkiri bahwa perubahan kurikulum dari tahun ke tahun mengalami perubahan, meskipun tidak semua yang direvisi namun hal ini harus dihadapi karena ini merupakan upaya menghadapi kebutuhan pasar yang secara terus menurus mengalami perubahan akibat perkembangan dan pertumbuhan bangsa ini. Untuk mengikuti perkembangan dan pertumbuhan ini perlu adanya inovasi dalam pengembangan kurikulum. Inovasi dalam hal ini harus dapat memberikan pengalaman berbeda dari kurikulum sebelumnya, kebutuhan keterampilan kerja saat ini perlu dikualifikasi karena setiap masyarakat saat ini perlu adanya kualifikasi untuk dapat berkerja.

Setiap SDM wajib memiliki sertifikasi keahlian tertentu sehingga dapat menjawab tantangan kesenjangan dengan tingginya kebutuhan pelaku industri akan tenaga ahli yang sudah teruji di bidangnya masing-masing (Bob Azam, Direktur Administration, Corporate \& External Affairs TMMIN). Kenyataan di lapangan saat ini menunjukkan bahwa keberadaan Sekolah Menengah Kejuruan sebagai peranan pemegang dalam menyiapkan tenaga kerja ternyata dinilai masih kurang untuk penyiapan lulusan siap kerja. Menurut Clarke (2007) mengatakan bahwa terdapat perbedaan tujuan antara dunia pendidikan dengan lapangan kerja/dunia industri karena sekolah hanya menginginkan lulusan yang memiliki nilai tinggi dalam waktu cepat sedangkan di dunia industri menginginkan lulusan berkompeten teknis dan sikap kerja yang baik.

Artikel ini bertujuan untuk mendeskripsikan perkembangan kurikulum pendidikan vokasional dengan kebutuhan dunia industri. Hasil penelitian ini diharapkan dapat memberikan manfaat baik secara teoritis maupun praktis. Secara teoritis penelitian ini dapat menambah wawasan mengenai perkembangan kurikulum pendidikan. Diharapkan dapat digunakan sebagai dasar dalam pengembangan ilmu pengetahuan yang ada kaitannya dengan pendidikan vokasional. Secara praktis bagi lembaga pendidikan, dapat memberikan bahan pertimbagan dan masukan dalam mengambil kebijakan terkait dengan kurikulum pendidikan vokasional.

\section{B. METODE}

Penelitian ini menggunakan pendekatan penelitian kualitatif dengan jenis penelitian desain penelitian deskriptif. Penelitian ini merupakan prosedur penelitian yang akan menghasilkan data deskriptif yaitu berupa kalimat tertulis dari beberapa sumber artikel. Teknik pengumpulan data 
dengan telaah kepustakaan di mana dalam pembuatan artikel ini dikutip dari artikel yang telah dipublikasi pada jurnal atau prosiding ilmiah.

\section{HASIL}

\section{Definisi Pendidikan Vokasional}

Pendidikan vokasional umumnya diartikan sebagai bagian dari pendidikan yang memberikan pengetahuan dan keterampilan terhadap suatu bidang atau suatu profesi tertentu.

Pendidikan vokasional merupakan tambahan untuk pendidikan umum, proses pembelajaran yang terkait dengan bidang ilmu pengetahuan dan teknologi, memperoleh keterampilan praktis, sikap kerja yang baik, pemahaman serta pengetahuan pekerjaan di segala sektor sosial dan ekonomi (UNESCO, 2001). Pendidikan vokasional merupakan salah satu pendidikan dengan tujuan utama untuk mempersiapkan individu bekerja dengan menggunakan pendekatan berbasis kompetensi (Pavlova, 2009).

Pendidikan keterampilan atau pendidikan vokasional saat ini diyakini menjadi salah satu pendidikan yang dapat mengurangi angka pengganguran. Hal itu disebabkan karena konsep pendidikannya mengutamakan skill atau keterampilan, menciptakan individu yang berkualitas, terampil, memiliki sikap kerja dan berjiwa kewirausahaan. Tujuan utama pendidikan vokasional adalah sebagai berikut;

a. Meningkatkan jumlah peserta pelatihan yang berasal dari pendidikan tingkat menengah tinggi

b. Mengembangkan pengetahuan dan keterampilan profesional yang diperlukan untuk praktik profesi

c. Mengevaluasi tingkat pendidikan peserta, agar menjadi individu profesional yang kompetitif di masa depan (Zarifis, 2000).

\section{Pengembangan Kurikulum}

Salah satu variabel penting untuk meningkatkan kualitas lulusan sekolah adalah kualitas kurikulum. Kurikulum merupakan seperangkat pembelajaran yang digunakan dalam pembelajaran di sekolah. Kurikulum bersifat dinamik, artinya kurikulum selalu mengalami perubahan kemajuan karena teknologi, masyarakat dan kebutuhan industri. Kurikulum juga dapat berasal dari potensi daerah seperti akademi komunitas yang merupakan perwujudan dalam menjawab persoalan dan tantangan yang ada dan muncul di daerah (Jalinus dkk., 2018). Agar pengembangan kurikulum menjadi efektif dan sekolah berhasil dalam penyiapan siswa yang siap kerja, guru dan industri harus dilibatkan dalam proses pengembangan kurikulum (Alsubaie, 2016).

Pengembangan kurikulum di Indonesia perlu partisipasi dari industri untuk menyelaraskan dengan perkembangan teknologi yang terus berkembang. Menurut Heider (2016) mengatakan bahwa partisipasi guru dalam proses pengembangan kurikulum akan membantu mereka 
memperbarui dan meningkatkan tidak hanya pada kurikulum tetapi juga untuk pengajaran yang lebih baik dan efektif dan proses belajar itu sendiri.

Upaya menyempurnakan kurikulum yang telah ada dengan melakukan perencanaan dan penyusunan kurikulum agar dapat dijadikan pedoman dalam pendidikan Nasional. Memasukkan materi yang selaras dengan kebutuhan dunia kerja merupakan salah satu upaya pengembangan kurikulum. Ada empat hal penting yang perlu diperhatikan dalam penyusunan kurikulum yaitu: (1) desain kurikulum harus mengacu kepada disiplin ilmu, (2) desain kurikulum harus berorientasi kepada masyarakat, (3) desain kurikulum harus berorientasi kepada siswa, dan (4) desain kurikulum harus berorientasi pada teknologi yang ada (Yoto dkk., 2013).

\section{Dunia Industri}

Hubungan kerja dengan dunia industri dilakukan oleh sekolah dengan tujuan mendidik siswa agar memiliki skill atau keterampilan dan kesiapan untuk memasuki dunia kerja nyata. Bentuk hubungan kerja dapat berupa kemitraan dalam pelaksanaa program pendidikan yang ada di sekolah. Bentuk dukungan dunia industri dalam pendidikan sekolah meliputi bantuan pengembangan kurikulum sekolah yang difokuskan pada pasar kerja sebagai upaya dalam menciptakan lulusan yang siap memasuki perkerjaan.

Untuk meningkatkan kompetensi yang selaras dengan dunia kerja pihak sekolah mewajibkan siswannya melaksanakan prakerin. Prakerin adalah proses pembelajaran siswa untuk dapat belajar sesuai dengan bidang keahliannya. Praktik Kerja Industri (PRAKERIN) merupakan salah satu bentuk pendidikan yang melibatkan siswa secara langsung bekerja di Dunia Usaha dan Dunia Industri (Imam Susanto dan Aris Ansori, 2015). Program prakerin ini bermanfaat bagi sekolah untuk membantu siswa meningkatkan skill dan pengetahuannya. Dunia industri sebagai mitra juga memberi kesempatan bagi siswa untuk mengembangkan kreatifitas pada tempat pendidikan yang lebih realistis. Pihak sekolah hendaknya dapat memanfaatkan kesempatan tersebut untuk pelatihan yang lebih efektif dalam pembentukan keterampilan dan sikap kerja profesional sesuai bidangnya.

Kompetensi yang diharapkan oleh Industri adalah keterampilan yang sesuai dengan bidangnya (hard skill) dan kompetensi lain seperti sikap, kerjasama, serta motivasi yang tergolong (soft skill). Kompetensi hard skills merupakan keterampilan yang digunakan untuk melakukan pekerjaan sesuai dengan bidang keahliannya, sedangkan kompetensi soft skills digunakan untuk mendukung dalam menyelesaikan setiap tugasnya (Nugroho Wibowo, 2016).

\section{Prinsip-Prinsip Pengembangan Kurikulum}

Menurut Asmariani (2014) mengatakan bahwa ada beberapa prinsip yang perlu diterapkan dalam pengembangan kurikulum, prinsip tersebut adalah; 
a. Prinsip relevansi, membuat kurikulum harus memeperhatikan kebutuhan dari lingkungan, masyarakat dan siswa, agar nantinya dapat berguna bagi siswa untuk bersaing dalam dunia industri/dunia kerja yang selalu berkembang serta harus sesuai dengan perkembangan teknologi masa yang akan datang.

b. Prinsip fleksibilitas, kurikulum harus mempunyai kemudahan dalam melakukan penyesuain dengan keadaan. Kurikulum yang baik adalah kurikulum yang berisi hal-hal yang solid, tetapi dalam pelaksanaannya dapat memungkinkan terjadinya penyesuaiaan-penyesuaian berdasarkan kondisi dari daerah.

c. Prinsip kontinuitas, perkembangan dan proses belajar anak berlangsung secara berkesinambungan, tidak terputus-putus. Oleh karena itu, pengalaman belajar yang disediakan pada kurikulum juga diharapkan berkesinambungan antara suatu tingkat dengan tingkat lainnya.

d. Prinsip efisiensi, kurikulum hendaknya dalam pengembangan tidak membutuhkan waktu, tenaga dan biaya yang besar.

e. Prinsip efektifitas, kurikulum harus mempunyai kemampuan dalam hal memenuhi tujuan dari apa yang telah direncanakan.

\section{PEMBAHASAN}

Pengembangan kurikulum menjadi strategi untuk pencapaian pendidikan Nasional. Untuk mencapai tujuan belajar yang dapat menghasilkan lulusan dengan daya saing tinggi, maka perlu adanya perbaikan dalam proses pembelajaran (Jalinus dkk., 2017). Pendidikan mengupayakan agar hasil yang diperoleh siswa ketika disekolah dapat memberikan kemampuan yang kompeten di bidangnya. (Kemenaker, 2017) mengatakan kurikulum SMK belum sesuai dengan dunia industri. Dalam pengembangan kurikulum yang disesuaikan dengan kebutuhan dunia kerja diharapkan lulusan dari sekolah menengah kejuruan bisa bekerja pada industri. Guru di sekolah saat ini tidak lagi sebagai penyampai materi, guru bertindak lebih sebagai panduan, penasihat, motivator, fasilitator jika di lab atau lokakarya kolaborasi guru dengan asisten laboratorium dan evaluator (Jalinus dkk., 2017).

Kegiatan pembelajaran di sekolah menengah kejuruan lebih banyak belajar praktek. Belajar praktek dapat terlaksana dengan optimal melalui penggunaan model pembelajaran yang tepat. Pengembangan model pembelajaran harus bisa memfasilitasi siswa untuk menguasai pengajaran bahan dan memberikan pengetahuan dan keterampilan tentang implementasi materi pengajaran (Jalinus dkk., 2017). Praktek belajar dalam pendidikan kejuruan adalah penyediaan pembelajaran bagi siswa untuk dapat memperoleh kemampuan operasional mesin, keahlian pemrograman, atau keahlian pemeliharaan (Jalinus dkk., 2018). Kurikulum pada SMK akan mengalami perubahan seiring dengan perkembangan teknologi. Sekolah dapat menerima kurikulum baru, namun untuk 
melaksanakan kegiatan praktikum khususnya sekolah tidak dapat melaksanakannya karena terkendala pada sarana dan prasarana praktik. (Mendikbud Muhadjir Effendy, 2018) mengatakan saat ini SMK akan dikembangkan sesuai dengan apa yang dibutuhkan industri. Hal ini menjadi sebab kenapa lulusan siswa Sekolah Menengah Kejuruan sulit untuk memasuki dunia kerja. Untuk mewujudkan kurikulum tersebut dapat dilakukan dengan pelaksanaa prakerin ke industri, prakerin ini dapat meningkatkan skill dan pengetahuan siswa yang sesuai dengan bidangnya.

Tujuan pengembangan kurikulum berbasis pada kebutuhan industri yaitu untuk melakukan kerjasama dalam meningkatkan skill atau keterampilan, menciptakan individu yang berkualitas, terampil, memiliki sikap kerja dan berjiwa kewirausahaan sehingga terjadi kecocokan atau kesesuaian dengan kebutuhan Dunia Usaha dan Dunia Industri (DUDI) termasuk masyarakat.

\section{E. KESIMPULAN}

Melalui pengembangan kurikulum pada Sekolah Menengah Kejuruan berbasis dunia industri bertujuan untuk meningkatkan skill atau keterampilan siswanya. Keahlian yang penting untuk menunjang kesiapan lulusan Sekolah Menengah Kejuruan yaitu soft skills dan hard skills. Kompetensi soft skills digunakan untuk mendukung dalam menyelesaikan setiap tugasnya sedangkan kompetensi hard skills merupakan keterampilan yang digunakan untuk melakukan pekerjaan sesuai dengan bidang keahliannya. Namun saat ini pelaksanaan kurikulum pendidikan vokasional belum sesuai pada kebutuhan Dunia Industri. Karna itu pendidikan di sekolah harus mampu menyediakan pendidikan yang sesuai dengan kebutuhan industri.

\section{DAFTAR PUSTAKA}

Asmariani (2014). Prinsip-Prinsip Pengembangan Kurikulum Dalam Perspektif Islam. Jurnal $A L$ AFKAR, 3(2).

Alsubaie, M. A. (2016). Curriculum Development: Teacher Involvement in Curriculum Development. Journal of Education and Practice, 7(9).

Clarke, M. (2007). Understanding and Managing Employability in Changing Career Contexts. Journal of European Industrial Training, 32(4), 258-284.

Heider, G., (2016). Process Of Curriculum Development In Pakistan. International Journal of New Trends in Arts, Sports \&Science Education, 5(2).

Imam Susanto dan Aris Ansori. (2015). Evaluasi Pelaksanaan Praktik Kerja Industri (PRAKERIN) Pada Mata Diklat Produktif di SMK Sunan Giri Menganti Gresik. JPTM, Volume 4 Nomor 1. 64-70.

Indriaturrahmi dan Sudiyatno. (2016). Peran Dunia Usaha dan Dunia Industri dalam Penyelenggaraan SMK Berbasis Kearifan Lokal di Kota Mataram. Jurnal Pendidikan Vokasi, 6(2): 162-172. 
Jalinus, N. et al. (2017). Improve Learning Outcomes of Students Through Implementation of The Collaborative Project-Based Learning Model in Thermodynamics. Proceeding the 1st International Conference on Education Innovation. pp. 559 -564.

Jalinus, N. et al. (2017). The Seven Steps of Project Based Learning Model to Enhance Productive Competences of Vocational Students. $1^{\text {st }}$ International Conference on Technology and Vocational Teacher (ICTVT 2017). Atlantis Press: Advances in Social Science, Education and Humanities Research. Volume 102. 251-256.

Jalinus, N. et al. (2017). Implementation of the Pjlb Model to Enhance Problem Solving Skill and Skill Competency of Community College Student. Jurnal Pendidikan Vokasi. Vol. 7. No. 3. pp 304-311.

Jalinus, N. et al. (2018). Mewujudkan Pendirian Akademi Komunitas Melalui Penerapan Model Project Based Learning. Jurnal Pendidikan Teknologi Kejuruan, 1(2), 51-58.

Jalinus, N. et al. (2018). The instructional media development of welding practice course based on PjBL model: enhancing student engagement and student competences. Int. J. Innovation and Learning, Vol. 24, No. 4.

Kemenaker: Kurikulum Penyebab Pengangguran Lulusan SMK Tinggi. http://infobanknews.com/kemenaker-kurikulum-penyebab-pengangguran/.

Mendikbud: Kurikulum SMK Akan Disesuaikan Dengan Kebutuhan Industri. http://www.tribunnews.com/metropolitan/2018/06/30/mendikbud-kurikulum-smk-akandisesuaikan-dengan-kebutuhan-industri.

Peraturan Pemerintah Republik Indonesia No. 29 Tahun 1990 tentang Pendidikan Menengah.

Wibowo, N. (2016). Upaya Memperkecil Kesenjangan Kompetensi Lulusan Sekolah Menengah Kejuruan dengan Tuntutan Dunia Industri. Jurnal Pendidikan Teknologi dan Kejuruan, 23(1).

Yoto. et al. (2013). Partisipasi Masyarakat Industri dalam Penyusunan Sinkronisasi Kurikulum di SMK. Jurnal Teknik Mesin, 21(1).

United Nation Educational, Scientific, and Cultural Organization, (2001). Revised Recommendation Concerning Technical and Vocational Education and Training. Paris, UNESCO.

Pavlova. M., (2009). Technology and Vocational Education for Sustainable Development.: Netherlands: Springer Netherlands.

Zarifis, G. (2000). Vocational Education and Training Policy Development for Young Adults In The European Union: a Thematic Analysis of the EU Trend of Convergence Towards Integration, Drown From the VET Policies Adopted In Three Member States. Research in PostCompulsory Education, Volume 5, Number 1. 91-113. 